\title{
TU/e Emphoven

\section{A five dimensional implementation of the flamelet generated manifolds technique for gas turbine application}

\section{Citation for published version (APA):}

Donini, A., Bastiaans, R. J. M., Oijen, van, J. A., \& Goey, de, L. P. H. (2015). A five dimensional implementation of the flamelet generated manifolds technique for gas turbine application. AlP Conference Proceedings, 1648, 030012-1/5. https://doi.org/10.1063/1.4912329

DOI:

$10.1063 / 1.4912329$

Document status and date:

Published: 01/01/2015

\section{Document Version:}

Publisher's PDF, also known as Version of Record (includes final page, issue and volume numbers)

\section{Please check the document version of this publication:}

- A submitted manuscript is the version of the article upon submission and before peer-review. There can be important differences between the submitted version and the official published version of record. People interested in the research are advised to contact the author for the final version of the publication, or visit the $\mathrm{DOI}$ to the publisher's website.

- The final author version and the galley proof are versions of the publication after peer review.

- The final published version features the final layout of the paper including the volume, issue and page numbers.

Link to publication

\section{General rights}

Copyright and moral rights for the publications made accessible in the public portal are retained by the authors and/or other copyright owners and it is a condition of accessing publications that users recognise and abide by the legal requirements associated with these rights.

- Users may download and print one copy of any publication from the public portal for the purpose of private study or research.

- You may not further distribute the material or use it for any profit-making activity or commercial gain

- You may freely distribute the URL identifying the publication in the public portal.

If the publication is distributed under the terms of Article 25fa of the Dutch Copyright Act, indicated by the "Taverne" license above, please follow below link for the End User Agreement:

www.tue.nl/taverne

Take down policy

If you believe that this document breaches copyright please contact us at:

openaccess@tue.nl

providing details and we will investigate your claim. 


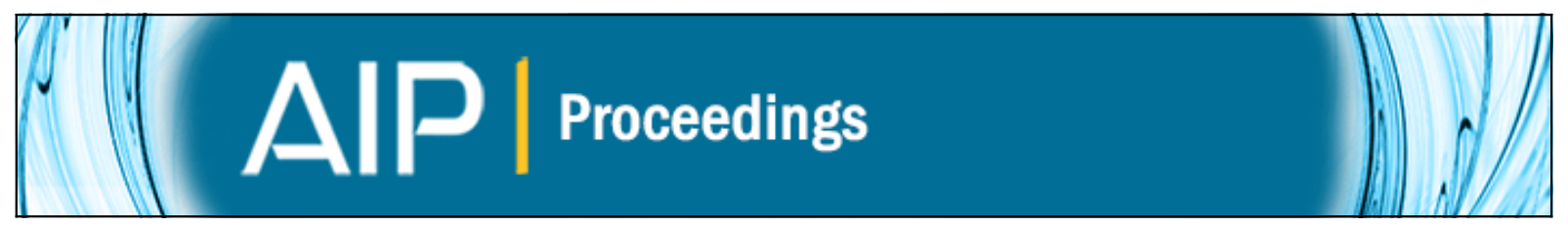

\section{A five dimensional implementation of the flamelet generated manifolds technique for gas turbine application}

A. Donini, R.J.M. Bastiaans, J.A. van Oijen, and L.P.H. de Goey

Citation: AIP Conference Proceedings 1648, 030012 (2015); doi: 10.1063/1.4912329

View online: http://dx.doi.org/10.1063/1.4912329

View Table of Contents: http://scitation.aip.org/content/aip/proceeding/aipcp/1648?ver=pdfcov

Published by the AIP Publishing

\section{Articles you may be interested in}

Towards numerical simulation of turbulent hydrogen combustion based on flamelet generated manifolds in OpenFOAM

AIP Conf. Proc. 1558, 168 (2013); 10.1063/1.4825447

High pressure jet flame numerical analysis of $\mathrm{CO}$ emissions by means of the flamelet generated manifolds technique

AIP Conf. Proc. 1558, 136 (2013); 10.1063/1.4825439

Green functions for wave propagation on a five-dimensional manifold and the associated gauge fields generated by a uniformly moving point source

J. Math. Phys. 47, 122902 (2006); 10.1063/1.2401692

Positive mass conjecture for five-dimensional Lorentzian manifolds

J. Math. Phys. 40, 3540 (1999); 10.1063/1.532906

Acoustic signatures of five wind turbine generators from 80-300 kW

J. Acoust. Soc. Am. 80, S28 (1986); 10.1121/1.2023731 


\title{
A Five Dimensional Implementation of the Flamelet Generated Manifolds Technique for Gas Turbine Application
}

\author{
A. Donini, R.J.M. Bastiaans, J.A. van Oijen and L.P.H. de Goey \\ Eindhoven University of Technology, Eindhoven, The Netherlands
}

\begin{abstract}
In the present paper the Flamelet-Generated Manifold (FGM) chemistry reduction method is implemented and extended for the inclusion of all the features that are typically observed in stationary gas-turbine combustion. These consist of stratification effects, heat loss and turbulence. The latter is included by coupling FGM with the Reynolds Averaged Navier Stokes (RANS) model. Three control variables are included for the chemistry representation: the reaction evolution is described by the reaction progress variable, the heat loss is described by the enthalpy and the stratification effect is expressed by the mixture fraction. The interaction between chemistry and turbulence is considered through a presumed probability density function (PDF) approach, which is considered for progress variable and mixture fraction. This results in two extra control variables: progress variable variance and mixture fraction variance. The resulting manifold is five-dimensional, in which the dimensions are progress variable, enthalpy, mixture fraction, progress variable variance and mixture fraction variance. In addition, a highly turbulent and swirling flame in a gas turbine model combustor is computed, in order to test the 5-D FGM implementation. The use of FGM as a combustion model shows that combustion features at gas turbine conditions can be satisfactorily reproduced with a reasonable computational effort. The implemented combustion model retains most of the physical accuracy of a detailed simulation while drastically reducing its computational time, paving the way for new developments of alternative fuel usage in a cleaner and more efficient combustion.
\end{abstract}

Keywords: combustion, chemical reduction, flamelet generated manifolds, turbulence, gas turbines; tabulation, stratification, heat loss PACS: 47.27.T-, 47.70.-n, 82.33.Vx, 47.70.Fw, 47.70.Pq, 47.27.E-

\section{INTRODUCTION}

The numerical modeling of reactive flows for industrial applications has gained a continuous growth of interest in the last few decades. This especially applies to the design of applications for which experimental investigations are complex and expensive, such as gas turbines burners. Gas turbine combustion is one of the most important energy conversion method in the world today. This is because using gas turbines, large scale, high efficiency, low cost and low emission energy production is possible. For this type of engines, low pollutants emissions can be achieved by very lean premixed combustion systems. This sort of combustion requires special attention to the balance between emissions, flame stability and completeness of combustion. Numerical simulation is foreseen to provide a tremendous increase in gas turbine combustors design efficiency and quality over the next future. However, the numerical simulation of modern stationary gas-turbine combustion systems represents a very challenging task. The interaction of turbulence, chemical reactions and thermodynamics in reactive flows is of exceptional complexity. The detailed simulation of the entire practical combustion equipment remains still prohibited in the next few decades, because of current and future limitations in computing power. This problem asks for a special treatment in the modeling of combustion chemistry, and its interaction with turbulence as well. To achieve a profound understanding of turbulent premixed combustion, the Flamelet-Generated Manifold (FGM) [1] technique is adopted in this work. The approach of FGM is based on the idea that the most important aspects of the internal structure of the flame front should be taken into account. In this view, a low-dimensional chemical manifold is created on the basis of one-dimensional flame structures, including nearly all of the transport and chemical phenomena as observed in three-dimensional flames. In addition, the progress of the flame is generally described by transport equations for a limited number of control variables. In the present case all the features that are typically observed in stationary gas-turbine combustion are included. These consist of stratification effects, heat loss to the walls and turbulence. Initially, three control variables are included for the chemistry representation: the reaction evolution is described by the reaction progress variable, the heat loss is described by the enthalpy and the stratification effect is expressed by the mixture fraction. The interaction between chemistry and turbulence is considered through a presumed probability density function (PDF) approach, which is considered for progress variable and mixture fraction. This results in two extra control variables: progress variable variance and mixture fraction variance. The resulting manifold is five-dimensional, in which the dimensions are progress variable, 
enthalpy, mixture fraction, progress variable variance and mixture fraction variance.

\section{FLAMELET GENERATED MANIFOLDS - FIVE DIMENSIONAL IMPLEMENTATION}

In this study we consider partially premixed methane/air combustion at atmospheric pressure conditions. The progress variable $\mathscr{Y}$ is chosen to be a linear combination of species mass $Y_{i}: \mathscr{Y}=\sum_{i=1}^{N_{s}} \alpha_{i} Y_{i}$. The weighting factors $\alpha_{i}$ are chosen to be: $\alpha_{\mathrm{CO}_{2}}=M_{C O_{2}}^{-1}, \alpha_{\mathrm{H}_{2}}=M_{\mathrm{H}_{2}}^{-1}, \alpha_{\mathrm{H}_{2} \mathrm{O}}=M_{\mathrm{H}_{2} \mathrm{O}}^{-1}, \alpha_{O_{2}}=-M_{\mathrm{O}_{2}}^{-1}$ and $\alpha_{i}=0 \forall i \notin\left\{C \mathrm{O}_{2}, H_{2}, H_{2} O, O_{2}\right\}$. The enthalpy is not conserved throughout the domain [2,3] because of the heat loss to the combustion chamber walls, and by means of radiation. Furthermore, fuel and oxidizer are not perfectly mixed. In order to take this into account in the tabulation process, the laminar flamelets have to be solved for different values of enthalpy $h$ and mixture fraction $Z$, introducing these two as control variables. The procedure for the chemistry tabulation with enthalpy and mixture fraction inclusion follows the description given in [4]. Chemistry is represented by the GRI-Mech 3.0 reaction mechanism [5] which contains 325 elementary reactions between 53 species. A unity Lewis number assumption is chosen during the calculation of the flamelets [6]. The turbulence-chemistry interaction is taken into account by describing variables in a stochastic way. Locally a variable is described by a Probability Density Function (PDF) defining the probability of occurrence of a certain state. This is therefore accounted for progress variable and mixture fraction by convolution of the laminar database using a $\beta$-function shaped PDF [7]. The $\beta$-pdf shape has the advantage of including singularities near the end points while being simple to compute. The integration operation generates an increase of two dimension in the manifold, which will finally reach the number of five dimensions for the present case. The final dimensions for the manifold are: progress variable $\widetilde{\mathscr{Y}}$, enthalpy $\widetilde{h}$, mixture fraction $\widetilde{Z}$, variance of progress variable $\widetilde{\mathscr{Y}^{\prime \prime 2}}$ and variance of mixture fraction $\widetilde{Z^{\prime \prime 2}}$. The chemistry data obtained by the tabulation procedure is rearranged through a coordinate transform, and the tabulated data is then directly retrievable as a function of the control variables. An illustrative overview of the resulting manifold can be seen in Figure 1, in which the progress variable source term is represented at the maximum level of enthalpy and zero variance of mixture fraction, as a function of the progress variable and equivalence ratio (i.e. mixture fraction, under the assumption of unity Lewis number), for different levels of variance of progress variable (in transparency). This data-set is stored in memory and associated to the CFD code. During run-

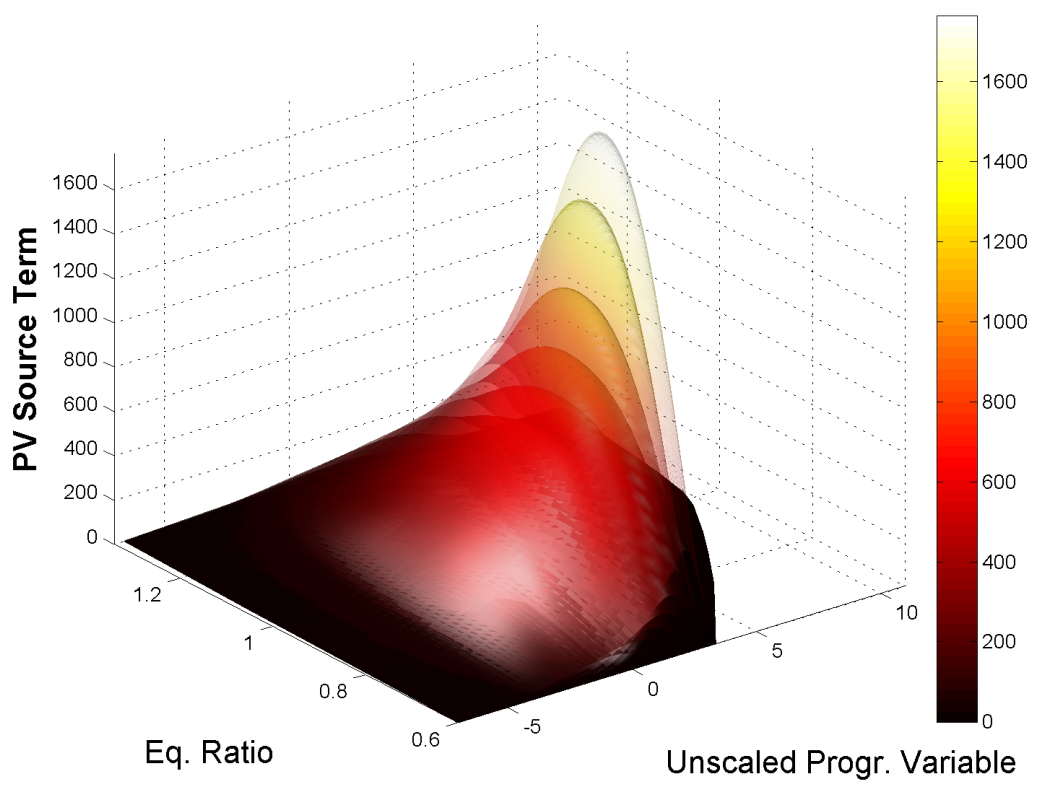

FIGURE 1. Representation of the 5D manifold at the highest enthalpy level and zero variance of mixture fraction. The surfaces show the progress variable source term $\left[\mathrm{kg} \mathrm{m}^{-3} \mathrm{~s}^{-1}\right.$ ] profile as a function of unscaled progress variable and equivalence ratio, at different levels of variance of the progress variable, shown with different transparencies.

time, together with the momentum and continuity equations, the CFD code must solve conservation equations for the progress variable, enthalpy and mixture fraction [4]. For the calculation of the variance of progress variable $\widetilde{\mathscr{Y}^{\prime \prime 2}}$ and 
variance of mixture fraction $\widetilde{Z^{\prime 2}}$ a suitable, and often used, model is the gradient-based model as described in [7, 2]:

$$
\widetilde{\mathscr{Y}^{\prime \prime 2}} \approx \frac{a^{2} \Delta^{2}}{12}\left(\frac{\partial \widetilde{\mathscr{Y}}}{\partial x}\right)^{2}=\alpha \Delta^{2}\left(\frac{\partial \widetilde{\mathscr{Y}}}{\partial x}\right)^{2}
$$

where $\Delta$ is the filter width, which is considered to be equivalent to the grid resolution. The parameter $a$ is assumed to be a constant, or determined by a dynamic procedure.

\section{TEST-CASE GEOMETRY, SCALES AND NUMERICAL METHODS}

In this section, a highly turbulent and swirling flame in a gas turbine model combustor is computed by means of 5-D FGM as a test case. The gas turbine model combustor, extensively studied experimentally e.g. in [9,8], is schematically shown in Figure 2 (left). Dry air at room temperature and atmospheric pressure is supplied to the combustion chamber through two concentric co-swirling nozzles. The central nozzle has a diameter of $15 \mathrm{~mm}$, while the annular nozzle has an inner diameter of $17 \mathrm{~mm}$ and outer diameter of $25 \mathrm{~mm}$, contoured by an outer exit diameter of $40 \mathrm{~mm}$. Nonswirling methane is fed through a non-swirled annular inlet, radially located between the air swirlers. The combustion chamber downstream the nozzle consists of a square section measuring $85 \times 85 \mathrm{~mm}$ with a height of $114 \mathrm{~mm}$. The plane of exit of fuel and central air nozzle is located $4.5 \mathrm{~mm}$ below the outer air nozzle exit plane. The latter is defined as reference plane $\mathscr{H}=0$. A conical top plate with a central exhaust tube (diameter $40 \mathrm{~mm}$, length $50 \mathrm{~mm}$ ) forms the outlet. In the experiments [8,9], three different operating conditions are investigated. Among these, the so called "flame A" is selected for the numerical analysis presented here. This operating condition is outlined by the following global parameters: thermal power $P_{t h}=34.9 \mathrm{~kW}$, air mass flow rate $\dot{m}_{a i r}=0.01825 \mathrm{~kg} \mathrm{~s}^{-1}$, fuel mass flow rate $\dot{m}_{\text {fuel }}=0.696 \mathrm{~g} \mathrm{~s}^{-1}$, global equivalence ratio $\phi_{\text {global }}=0.65$ and global adiabatic flame temperature $T_{a d, \text { global }}=1750$ $\mathrm{K}$. The split ratio between air mass flowing through the annular and central nozzle is approximately 1.5. The swirl number calculated from the experimental velocity profile just above the nozzle exit is $S=0.9$. Heat loss to the walls is imposed by enforcing a temperature $T_{w}=800 \mathrm{~K}$ to the walls. The solver used for the simulations is Ansys-CFX 14.5 [10], coupled with the above described five-dimensional FGM implementation. The Reynolds Averaged NavierStokes (RANS) approach is used for turbulence, with a SSG Reynolds Stress Model The algorithm of the software is implicit and pressure-based, and the solver makes use of a conservative finite-element-based control volume method. The solver chosen for the computations of this work is incompressible. For the progress and control variable transport equations the turbulent Schmidt number is considered to be constant and equal to $S c_{T}=0.7$. The mesh is composed of 3200000 hexahedral/tetrahedral elements over 1700000 nodes, featuring an adequate refinement on the inlet ducts and flame zone (in this region the grid size is $\Delta_{x}=0.5 \mathrm{~mm}$ ).
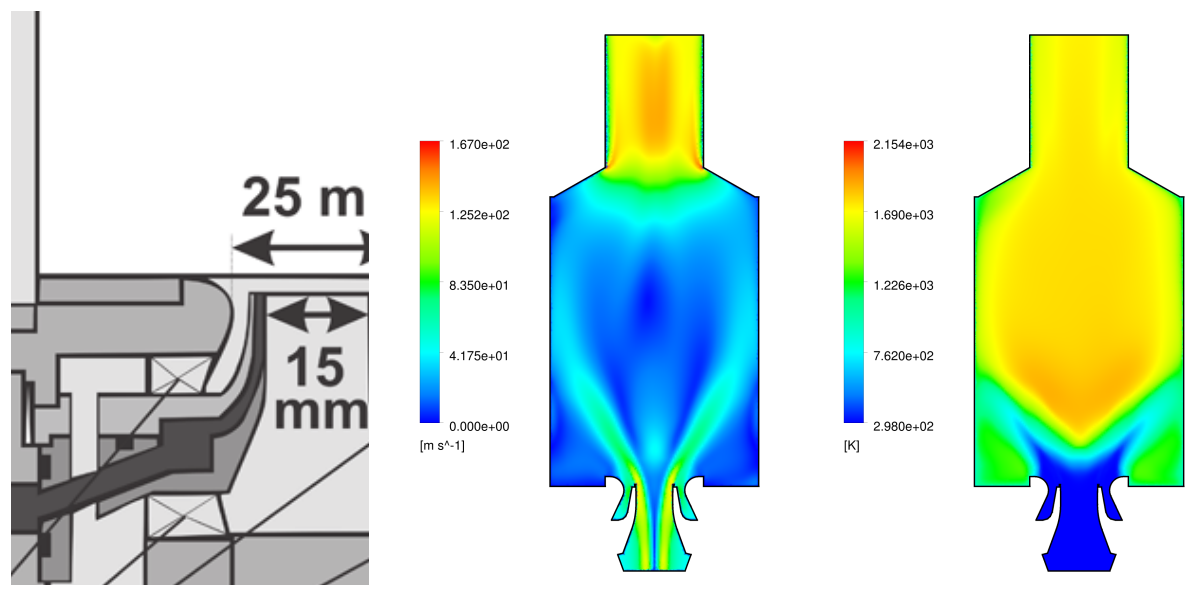

FIGURE 2. Left: schematic representation of the gas turbine model combustor geometry. Center: view of velocity magnitude at a central section plane $\left[\mathrm{m} \mathrm{s}^{-1}\right.$ ]. Right: temperature at a central section plane [ $\left.\mathrm{K}\right]$. 


\section{TEST RESULTS}

Figure 2 (center) shows the structure of the velocity field in the combustor. The stream of inlet gas forms a cone-shaped flow which extends to the outer wall, while centrally above the nozzle an inner recirculation zone (IRZ) opposes to the inlet gas stream, and an outer recirculation zone (ORZ) is observed externally to the nozzle at the dump plane edges. The effects of the rotating motion creates a vortex tube along the centerline of the combustor, which begins in the IRZ and extends to the outlet. This is in accordance with the experimental observations $[8,9]$. Figure 2 (right) displays the temperature field in the combustor. The temperatures of the outer recirculation zone are in good agreement with the experiments. In this region the temperature is strongly influenced by the heat loss to the wall.

\section{CONCLUSIONS}

The chemistry reduction method FGM is extended to five dimensions and coupled with RANS turbulence model, in order to predict the evolution and description of a turbulent partially premixed swirled flame, including the important effect of heat loss to the walls. Overall, the FGM method parameterized by the five dimensions $\widetilde{\mathscr{Y}}, \widetilde{h}, \widetilde{Z}, \widetilde{Y^{\prime \prime 2}}$ and

$\widetilde{Z^{\prime \prime 2}}$ has proven to capture well the structure of partially premixed swirled flames, which closely resembles gas turbine conditions. The relatively poor turbulence model (RANS) is judged to be the principal source of mismatch with the experiments, since it leads to an incorrect prediction of the recirculation regions, which are source of large scale instabilities. In conclusion, the study given in the present section represents a valuable initial test of the current FGM implementation. However, in order to achieve an improved numerical description and a more relevant comparison with the experiments of the current geometry, future work should aim to perform unsteady investigations (e.g. LES) with the current FGM implementation. The calculation time for the solution of the case here described (five-dimensional implementation of FGM) is in the order of 80 CPU-hours, which is notably low considering the complexity of the geometry. This proves the advantages given by the FGM reduction model, conveniently enabling to perform the aforementioned unsteady investigations in future works.

\section{REFERENCES}

1. J.A. van Oijen and L.P.H. de Goey, Modelling of Premixed Laminar Flames Using Flamelet-Generated Manifolds, Combustion Science and Technology, 161(1), 113-137 (2000).

2. A. Donini, S.M. Martin, R.J.M. Bastiaans, J.A. van Oijen and L.P.H. de Goey, Numerical Simulations of a Premixed Turbulent Confined Jet Using the Flamelet Generated Manifold Approach with Heat Loss Inclusion, Proceedings of the ASME Turbo Expo, GT2013-94363 (2013); doi:10.1115/GT2013-94363.

3. A. Donini, S.M. Martin, R.J.M. Bastiaans, J.A. van Oijen and L.P.H. de Goey, High pressure jet flame numerical analysis of $\mathrm{CO}$ emissions by means of the flamelet generated manifolds technique, AIP Conference Proceedings, 1558, 136 (2013); doi: $10.1063 / 1.4825439$.

4. A. Donini, Advanced Turbulent Combustion Modeling for Gas Turbine Application, Technische Universiteit Eindhoven, ISBN:978-90-386-3619-1 (2014).

5. G.P. Smith, D.M. Golden, M. Frenklach, N.W. Moriarty, B. Eiteneer, M. Goldenberg, C.T. Bowman, R.K. Hanson, S. Song, W.C. Gardiner, V.V. Lissianski and Z. Qin, GRI-Mech 3.0, http://www. me.berkeley.edu/gri_mech/.

6. N. Peters, Reducing mechanisms, in Reduced Kinetic Mechanisms and Asymptotic Approximations for Methane-Air Flames, Springer Verlag, 48-67 (1991).

7. A. Vreman, J.A. van Oijen, L.P.H. de Goey and R.J.M. Bastiaans, Subgrid Scale Modeling in Large-Eddy Simulation of Turbulent Combustion Using Premixed Flamelet Chemistry, Flow, Turbulence and Combustion, 82(4), 511-535 (2009).

8. P. Weigand, W. Meier, X. R. Duan, W. Stricker and M. Aigner, Investigation of Swirl Flames in a Gas Turbine Model Combustor I. Flow-Field, Structures, Temperature and Species Distributions, Combustion and Flame, 144 205-224 (2006).

9. W. Meier, X. R. Duan, and P. Weigand, Investigation of Swirl Flames in a Gas Turbine Model Combustor II. Turbulencechemistry interactions, Combustion and Flame, 144 225-236 (2006).

10. Ansys CFX Software, General Purpose Fluid Dynamics Program, http://www . ansys . com. 